\title{
Keep It Simple: Challenges, Solutions, and Best Practices for Global eLearning Initiatives
}

\author{
http://dx.doi.org/10.3991/ijac.v8i2.4622 \\ Kristen Giovanis \\ KJ International Resources, Minneapolis, United States
}

\begin{abstract}
Creating effective global eLearning initiatives requires strategic planning and process development to avoid mistakes that can turn off global learners. In order to successfully implement a global training program in a cost effective, efficient way, corporations must consider budget, timing, design, and content relevancy. These factors become more complex when considering lingual, regional and cultural differences across the globe. Preparing to face these complex challenges with stakeholder buy-in, defined procedures, and inter-department collaboration will ensure the success of the global initiative.
\end{abstract}

This article will explore eLearning best practices and methods when applied to a global audience, and address common pitfalls that can result in inefficiencies and miscommunications.

\section{INTRODUCTION}

The process of creating effective, impactful eLearning materials for international learners requires a broad understanding of the material being taught, the learners absorbing the information, and the limitations of the technology delivering the eLearning program. Companies have to think strategically and collaboratively about the structure and the outcomes they hope to achieve before any eLearning content is created. Well-built global eLearning programs can help companies drastically cut travel and employee training costs, improve efficiency, and help build a cohesive international company culture. However, companies face several challenges when creating an eLearning initiative, so preparation is required to avoid unnecessary cost and excessive delays in rolling out the materials. A basic knowledge of the best practices for eLearning content creation can help corporations avoid hiccups and cultural mistakes that could compromise the effectiveness of the lessons and the access international learners have to eLearning materials.

\section{COMMON TERMS DEFINED}

Before delving deeper into eLearning best practices, challenges, and creation guidelines, it's important to have an understanding of a few terms.

eLearning: Also known as "Electronic Learning" - this can be thought of as training programs powered by technology. In this information age where demand for online content is high, eLearning tools have become popular methods of dispersing documents, teaching students and training employees. eLearning formats can include, but are not limited to, videos, slideshows, documents, PDFs, live online classes (webinars), chat and message forums.

mLearning: Also known as "mobile learning," this type of eLearning uses portable technology like handheld computers, tablets, smartphones, and mp3 players to provide learning content like videos, exams, and slideshows for learners on the go. mLearning has a variety of applications, from workforce training to classroom learning.

Translation: This is simply the process of accurately converting the meaning of words from a source language to another language or languages. The primary concern of translation is accuracy; the process does not account for contextual relevance.

Localization: After translation of content takes place, localization is the process of adapting a product or a message to a different culture or cultures. This may involve research and study of the intended cultural norms, lingual differences, and market distinctions, making changes to the product or message accordingly.

\section{ELEARNING MARKET EXPANSION}

Well-executed eLearning programs utilize adult learning best practices and instructional design methodologies to create self-paced training using multimedia presentations. These have obvious applications in higher education, but the market for eLearning services and platforms is growing rapidly in the corporate environment. For businesses, the primary use of eLearning programs is for employee training and client onboarding.

In fact, a report from Research and Markets ${ }^{[1]}$ a publishing house for market research data, recently put out a report predicting that between 2015 and 2019, the global eLearning market will grow at a CAGR of 15.06 percent. Analysts point to tablet use (mLearning) driving this growth, as tablets more than PCs or notebooks promote easy interaction with the platform - with a touch screen. Additionally, "software as a service" or SaaS platforms are growing in popularity. These platforms are navigated to on the internet - little to no setup is required by the user - and they can be subscription-based for corporations who don't want to invest in a particular kind of software. These can be efficient solutions in many cases.

\section{Global Business Advantages}

One of the main reasons corporations move to eLearning solutions instead of traditional, in-person training methods is the ease of use and efficiency of these programs. For global corporations, eLearning solutions are very cost-effective, lowering travel costs, printing costs and other associated material costs traditionally associated with corporate training. eLearning solutions focus on the learner; they can be self-paced and interacted with individually, at any time. This eases the strain of launching an eLearning initiative while juggling international time zones and work schedules. 
When done correctly, these programs are also consistent each and every time - resulting in the same messaging and lesson focus in any language or culture. eLearning allows global corporations to track the progress of the learner, which is useful both for the person being trained as well as for the organization as a whole, especially since in-person training might be difficult to achieve across substantial distance. As a general rule, they also tend to significantly compress the amount of time traditional training takes, while still providing real-time access to the training materials and lessons.

\section{Four Challenges AND SOlutions For COPRORATIONS AdOPTING GLOBAL ELEARNING PROGRAMS}

\section{Challenge 1: Creating a strong eLearning "voice"}

Because there is no singular point of view or "voice" that will translate across all cultures, corporations risk turning off international learners when they make translation or localization errors. Researching the cultural norms and dialects of the specific country or region for an eLearning initiative can help mitigate this risk - but the research process can take time and money.

\section{Solution: Write for a global audience}

At first glance, "writing for a global audience" might seem to be an obvious solution to the challenge of cultural and lingual diversity. However, writing for a global audience actually involves quite a bit of thought and strategy and may require companies to edit eLearning programs heavily before translation and localization. For example, any reference to popular culture should be removed from eLearning copy and design, including sports, slang, entertainment, and other U.S.-specific reference. Writing for a global audience rewards brevity and clarity of both copy and graphic design.

\section{Challenge 2: Creating universal messaging}

While it may be tempting to adapt eLearning materials originally created for learners in one location to learners speaking a different language and belonging to a different culture, much can be lost in the translation and localization process. For example, a U.S. based eLearning training program may have great outcomes in the States, and be completely incoherent for learners in Turkey after translation and localization takes place. Developing copy and design that isn't referential to the source language can be very challenging, especially with limited knowledge of the new cultures and global regions being targeted. Creating an eLearning program that is both effective and easily localized to new cultures can be a hurdle that's set quite high without the right resources and knowledge.

\section{Solution: Keep localization in mind when creating the program}

This is not to say that all references or design items native to language and culture won't translate or localize well. If the eLearning program is written with the global audience in mind, without idioms, humor, or specific cultural citations, it may just be a matter of adapting the overall message of the program. Keeping this wide-angled view on outcomes - what the learners should absorb after the eLearning program is completed - can help trainers see a verbal or design work around for the localization or translation issue at hand. One example of this is the way some U.S.-based medical device companies market products that reduce patient hospital stay by a set number of days. In the United States, this data is compelling, as the overall trend in healthcare focuses on making patients better, faster. In European markets, this message doesn't translate as well. In most European countries, the healthcare best practice is to keep patients in hospitals for longer periods of time to ensure proper healing. While there is likely still an interest in faster healing in these countries, the specificity of fewer days in the hospital doesn't necessarily spell out a better product in these cultures. For that reason, U.S.-based medical device companies may localize the length of stay data to percentages rather than days. Speeding up patient healing by $60 \%$ would likely be a more effective message than reducing hospital stay by 6 days, for example.

Challenge 3: Translation and localization costs build with more global targets

Nearly every corporation will have to overcome the challenge of mounting costs when translating and localizing of eLearning materials. Especially when launching eLearning curricula into several nations with varying language and cultural norms, the "global language multiplier" will come into play - meaning, the more languages and cultures the materials need to match, the higher the costs of localization and translation will be.

Solution: Keep brevity and simplicity in mind during development

To effectively and efficiently manage cost and time of eLearning localization and translation projects, corporations have to spend time creating internationalized materials and language. This may mean that certain design or content delivery methods won't be appropriate for international audiences. For example, avoiding audio narration with animated video can be a smart decision in many cases - it's extremely expensive to translate voiceovers, time consuming to re-record them, and tricky to re-sync them with animation. To avoid this high cost and loss of time, "audio bookends" can be created to frame the animation and contextualize it, removing the issue of exact timing.

Whenever possible, consider the length of the program and try to keep word count to a minimum. Focus on what counts for the lesson efficacy. Although many use eLearning program as a "marketing tool," the reality is that the training should be just that: training. Editorializing eLearning to incorporate marketing messages doesn't typically help learners - and thus, doesn't generally help improve global eLearning outcomes.

Challenge 4: Diversity of technology options and variance in connectivity worldwide

Selecting a single platform and format for an eLearning program can pose a challenge to corporations in several ways. There are a plethora of options to choose from, ranging from the very basic off the shelf type eLearning solutions to the very complex, customized models that may also be quite expensive. Additionally, choosing which format to create could determine the effectiveness of the program in unexpected ways. Computer access and internet speeds vary greatly depending on the region and culture, so streaming video and $100 \%$ web-based programs with large graphical interface files may not be the best choice, for example. In countries where bandwidth is limited, and entirely new program may need to be devised.

Solution: Set technological objectives ahead of time 
It's important to have clear expectations of technical solutions for eLearning programs. For example, a highpowered, high dollar technology solution will likely have far more complexity than a lower cost, off-the shelf model. While there are limitations to each, corporations should set clear budgets and goals for the eLearning program and choose technological solutions appropriately. Considering both short and long term objectives for the eLearning program is the first step to creating a realistic and effective interface. From there, finding a technology that's designed with a modular approach that's widely interoperable with other technologies the global learners may have and that the corporation already possesses is the next evolution of the selection process.

Another important thing to keep in mind is the ability of the technology to be localized. A significant shift is underway in the eLearning technology development industry to try to make solutions that can quickly and seamlessly be adapted to multiple cultures and languages from inception to final delivery. Finding a technological solution that can shift from one culture to the next will save corporations time and money with a global eLearning program initiative.

\section{PlanNING REQUiREMENTS}

Before rolling ahead with an eLearning initiative, it's important to create an effective plan and get appropriate buy-in within an organization. Global stakeholder agreement on technology, messaging, branding, and goals of the eLearning module is the first planning milestone that will help organizations create training programs for inter- national learners. eLearning materials and lesson creation is not easily divided amongst many departments in the planning stages - it may take several meetings of key contributors to collaboratively create this plan and agree upon the steps to carry out the initiative. The complexity of the eLearning materials should be considered and planned strategically to avoid cost barriers and delayed rollout.

\section{CONCLUSION}

Corporations that create successful eLearning initiatives typically spend quite a bit of time developing a strategic plan for globalization. From the very beginning, content should be created with translation and localization in mind in order to produce effective lessons that can be easily adapted from one language or culture to another. Ultimately, this will save time, money, and effort while producing engaging lessons appropriate for a global audience.

\section{REFERENCES}

[1] Global E-Learning Market 2015-2019, Elmhurst, IL: TechNavio, 2014 http://www.researchandmarkets.com/research/v2rv6v/global elearning

\section{AUTHOR}

Kristen Giovanis is the CEO of KJ International Resources, Ltd. in Minneapolis, MN USA (email kgiovanis@kjinternational.com)

Submitted 14 April 2015. Published as resubmitted by the author 02 June 2015.

\section{APPENDIX}

\section{Best Practices for Corporate eLearning Initiatives}

1. Identify need: A global business need should be highlighted for every eLearning course or program. This focus on prioritization will ensure a clear purpose for each eLearning training and aid in simplification of language and visual choices.

2. Develop standards: From language choices to styles/graphics for consistent look and feel, eLearning programs should follow a corporate standard for formatting and content. Standards also help facilitate efficiency during the creation phases as well as during the translation/localization phase.

3. Talk to the experts: Use input from subject matter experts early and often in development. This is yet another way to efficiently create effective eLearning programs.

4. Measure, track, and report outcomes: Adjustments to lessons should be made as necessary. This is especially important when launching in different countries and cultures - what worked in one location may fall short in another. Making adjustments to the eLearning program based on targeted data can help corporations target the learners they need to reach.

5. Consider global technological differences: Internet speeds and access vary worldwide, it's important to plan formatting and design accordingly. Large video files and graphics may cause crashes and slow load times for international learners. Alternative eLearning formats like mLearning applications (apps) may be a solution in countries where bandwidth is limited.

6. Control vocabulary and terms: Idioms and cultural references will never translate or localize well. Remember that eLearning training is just that: training. Clever turns of phrase may fall on culturally deaf ears in an international arena.

7. Build a localization kit: This should include project instructions, source files, timelines, reference materials that translation and localization vendors can use. Localization kits help keep costs low and projects on-time, ensuring minimal miscommunication with the language services provider (LSP) or localization professional.

8. Write for the big, global picture: The wide-angled view of corporate trainng objectives may reveal the best way to format and write a global eLearning program. Knowing which terms and cultural items (colors, symbols, etc.) have the potential to offend or confuse an international learner can help keep lessons dialed-in to the broadest possible audience. 